\title{
Domestic Violence Behaviors between Spouses in Thailand
}

\author{
Kasetchai Laeheem ${ }^{1} \&$ Kettawa Boonprakarn ${ }^{1}$ \\ ${ }^{1}$ Faculty of Liberal Arts, Prince of Songkla University, Hatyai, Thailand \\ Correspondence: Kasetchai Laeheem, Faculty of Liberal Arts, Prince of Songkla University, Hatyai 90110, \\ Songkhla, Thailand. E-mail: Lkasetchai@yahoo.com
}

Received: May 24, 2014 Accepted: July 2, 2014 Online Published: July 24, 2014

doi:10.5539/ass.v10n16p152 URL: http://dx.doi.org/10.5539/ass.v10n16p152

\begin{abstract}
This article aims to review concepts, theories, and research reports related to domestic violence between spouses in Thailand, especially its meanings, types, causes, and effects. It is a documentary research, which concludes descriptive analysis to obtain a body of knowledge using a holistic approach. The outcomes of the research reveal that domestic violence between spouses in Thailand is patterns and ways that individuals use force to hurt others' health, physically, mentally, and sexually. They force, threaten, injure, detain, delay, molest, ignore, and invade personal rights and freedoms. Domestic violence can be classified into self-violence, violence between individuals, and violence between groups. It can also be classified into physical, mental, and sexual violence. Important causes of domestic violence derive from a belief that men have power to dominate their families, and other causes include environments that contribute to violence, childhood experiences, conflict, stress, and lack of time with each other. These can result in injury, lessons instilled in children, violence absorbed by children, unhappy families, runaway children, and divorces. In addition, domestic violence between spouses can be chaotic and disturbing for the community, and incur expenses to the government in looking after victims, hiring personnel, and campaigning to terminate and prevent the problem. Thus, parents and guardians must realize and give importance to avoidance of domestic violence. Individuals and organizations concerned must cooperate in promoting happy family life, and countering domestic violence between spouses.
\end{abstract}

Keywords: domestic violence, behaviors, family, violence between spouses

\section{Introduction}

Domestic violence between spouses has long been an important problem in Thai society that affects victims, abusers and family members who perceive and witness it. At present, society does not give enough importance to it because domestic violence between spouses is considered a personal matter, a problem of family members only, a problem of human rights violation, and a problem that outsiders should have nothing to do with. As a result, it is a hidden social problem that has become more complex and difficult to prevent and solve (Pradabmuk, 2003; Kungsakon \& Pojam, 2008). This is because nowadays Thai families are diverse and family relationships have changed with economic and social conditions. More husbands and wives have to go out to work to earn enough money for the family's cost of living, so they have less time to talk to each other. Sometimes they are confused about their duties and roles they should play in their family. This weakens the family and affects family relationships, family members have conflict but try not to express their unpleasant feeling which when accumulated for a long time can cause stress in the family. Eventually, conflict takes place followed by the problem of domestic violence between spouses (Puawongpaet, 1994; Parimutto, 2010).

Domestic violence between spouses is the behavior and actions which infringe personal rights in the form of physical, psychological, verbal and sexual assault by forcing, intimidating, physically harming, threatening, and hindering freedom both in the public and in private life. It can be physical and/or psychological assaults on each other resulting in the victim suffering both psychologically and physically. Assaulting women by a spouse or husband is one form of violence against women; it cuts off the woman's rights in her body and life and obstructs the existence of sex equality and the development of peacefulness. Violence against spouses is the connection between conflicts and violence and hence makes it difficult to prevent since many people in the society believe that disagreements or conflicts between husband and wife are normal to all families so the problem is usually dealt with only when it becomes serious and eventually violent. (Wichitranon \& Phongwet, 2000; Yoddamnoen-Adtidge, 2003; Phromrak, 2007; Supanichwatana \& Laeheem, 2017). 
Domestic violence between spouses often makes family imbalanced and leads to many more complicated problems such as broken homes, deserted children, uncared-for elderly, etc. Each time a problem of violent behavior happens in the family, it affects the victim and other members of the family. As it is said that violence done to the wives can cause a lot of economic burden to society in terms of medical treatment, social welfare, counseling provision, and prevention measures, etc. Moreover, it affects them mentally and emotionally, and it affects children's learning and absorption of the feeling (Puawongpaet, 1994; Kanjanakul, 1997). Additionally, the victims are not only injured physically but also psychologically which can remain in their memory all their life. Such domestic violence can also cause separations, divorces, and runaway children (Promrak, 2007).

The abovementioned problems indicate that domestic violence between spouses is still a hidden problem that is complicated and increasingly more violent in all societies. Nowadays, domestic violence has become a problem related to human rights violation by the state that affects women and children in a widest range, and it is considered physical violence that is closely connected to structural violence such as biases including gender bias, racial bias, skin tone bias, being pressed, and being oppressed, etc. Male dominance or male dominated societies with violence and competition may exist in normal everyday life practice but domestic violence between spouses has become structural violence that is difficult to solve because it is increasingly more complicated and violent (Puawongpaet, 1994; Kanjanakul, 1997; Promrak, 2007; Parimutto, 2010).

This article aims to review the concepts, theories, and research reports related to domestic violence between spouses by investigating meanings, types, causes, and effects of domestic violence between spouses in Thailand. The results of this study will provide knowledge, understanding, and data for related personnel to use in finding ways to solve and prevent the problem as well as for individuals who desire to conduct further studies into domestic violence.

\section{Methods}

This documentary study analyzes and synthesizes concepts, theories, and research reports related to domestic violence between spouses in Thailand from books, textbooks, and research in the country. The analysis and synthesis place emphasis on four issues: 1) meanings of domestic violence between spouses; 2) types of domestic violence between spouses; 3) causes of domestic violence between spouses; and 4) effects of domestic violence between spouses in Thailand. Then the data are classified into categories, and conclusions are drawn from descriptive analysis to obtain body of knowledge using holistic approach.

\section{Results}

\subsection{Meanings of Domestic Violence between Spouses in Thailand}

Domestic violence between spouses in Thailand is behavior showing intention to use force or physical power to threaten or to harm others or to violate personal rights physically, verbally, mentally, or sexually by forcing, threatening, hitting, kicking, punching, limiting, and obstructing rights, and freedoms in pubic or personal life. This can result in physical and mental suffering for the victim (Arpapirom, 2000; Wichitranon \& Phongwet, 2000). It is the use of power apart from the use of physical strength to harm others. It is an action arising from power relationship, threatening or intimidating using power, leaving or ignoring which result in physical, mental and sexual suffering, committing suicide, and self-injuring in various ways, which happens immediately or years after the first violence (Pongwech \& Wijitranon, 2000; Yoddamnoen-Adtidge, 2003).

In addition, domestic violence between spouses in Thailand refers to males' behavioral patterns of hurting females or their wives physically, mentally and sexually in order to show power in controlling them. It also refers to wives who are hurt by their husbands physically, mentally, and sexually time after time in order to force or threaten them to do something for their husbands without consideration of their personal rights (Phromrak, 2007; Parimutto, 2010). It is a pattern and type of action that a husband injures his wife or a wife injures her husband that results in the victim's physical, mental and sexual injury or behavior that violates forces, threatens, and injures each other. Besides, it refers to being abandoned, being confined, not being taken care of, and not being looked after (Friends of Women Foundation, 1989; Pichaisanith, 1997; Friends of Women Foundation, 2013). Domestic violence between spouses in Thailand also refers to using force to harm physically, mentally, sexually or to harm life, and to violate rights and freedoms in various ways, which are unfair actions in order to get power to control over them or to make them yield (Pakjekwinyusakul, Jamsutee, \& Nettayasupa, 2003; Punamsap, 2005). Domestic violence between spouses in Thailand is incidents taking place between couples inside and outside the home such as violence against wives, and violence against husband with a purpose to hurt them physically, mentally, emotionally as well as to harm their health, rights, and freedoms. This is done by misuse of force or power to make each couple do or not do and accept the action (World Health Organization, 2000; Ministry of Social Development and Human Security, 2007). 
The 2013 annual summary report of the frequency of domestic violence between spouses in Thailand by Violence against Children and Women and Domestic Violence Information Center (2013) showed that the frequency of domestic violence between spouses were rather high during 2010 up to 2013. There were 949 cases of violence in 2010, 1065 cases in 2011, 887 cases in 2012 and 776 cases in 2013. As can be seen, the frequencies did not decrease to the level in 2008 of only 54 cases. Domestic violence between spouses' scenarios reflect the reality that the assault of a wife has continually become more serious in degree. Husbands who assault their wives were of all economic status, occupation, nationality or religion (Supanichwatana \& Laeheem, 2017). The statistics showed that there were 22,639 cases of women seeking asylum at the One Stop Crisis Center (OSCC) in 2011. Among them, 8,336 cases (36.82\%) were those with the spouses who assaulted being family members or closely-related persons and 1,950 cases (8.61\%) being strangers. Besides, it was found that husbands were the persons who assaulted their wife most frequently (5,786 cases, $52.03 \%)$ and such assaults eventually led to divorces (One Stop Crisis Center, 2011).

The meanings above can be summarized as follows. Most domestic violence between spouses in Thailand is done by husbands or wives. The physical, psychological and sexual assaults on women is done to exhibit male power of the husband to force the woman to do something that he wants her to do or not to do without considering her personal rights. The husbands use different forms and levels of intensity which can be physical attack, causing physical wounds ranging from minor to more serious ones or even death if weapons are used. Physical assaults not only hurt physically but also psychologically. This so-called 'domestic violence between spouses' not only means physical assault which could yield psychological wounds as well but also means verbal assaults like cursing, speaking sarcastically and ridiculing with sarcasm. Besides, there is violence not done by physical or verbal assaults but by the husbands' behavior that causes psychological wounds such as adultery, having other women, or having minor wives. These result in psychological pain and eventually the use of verbal, physical and psychological assaults that hurt the victims physically, psychologically and verbally (Supanichwatana \& Laeheem, 2017).

\subsection{Types of Domestic Violence between Spouses in Thailand}

Domestic violence between spouses in Thailand can be classified in many ways depending on viewpoints or classification criteria. It is mostly classified into two forms: the person committing it, and the action committed. Domestic violence classified according to the person committing it can be further classified into three types. Type 1 is self-violence which refers to violence committed against oneself such as suicide, self-harm, self-targeting or putting oneself at risk or in danger, etc. after the husbands against wives or the wives against husbands. Type 2 is violence between individuals, which refers to violence committed by other individual or other groups of people or violence occurring between members of the family; especially domestic violence between spouses and it is not necessary for it to happen only at home. This includes sexual violence, rape, molestation, and abandonment, etc. Type 3 is violence between groups, which refers to violence committed by large groups of people including hidden form of violence as social norms that are used as tools against individuals or gender inequality or discrimination, such as violence related to social issues between husbands and wives, violence from hatred between husbands and wives, and violence by protesters between husbands and wives, etc. (Hemmanad, 1990; Oopyokin, 1995; Arpapirom, 2000; Songsumpan, 2002).

While, domestic violence between spouses in Thailand can be classified according to the actions into three types as follows. Type 1 is physical violence, which refers to the use of force or a tool as weapon to hurt the victim such as pushing, slapping, hitting, punching, beating, jerking, squeezing the neck, throwing thing at, and injuring severely with a weapon or a sharp object, etc. Type 2 is mental violence, which refers to any action or ignoring to act which causes the victim sorrow or losing rights or freedoms by doing it verbally or through gestures and action such as verbal despising, satirizing, scolding, bawling, yelling, embarrassing, being indifferent, threatening, showing anger, etc. Type 3 is sexual violence, which refers to the incident when a husband abuses his wife, a father abuses his children, an elder relative such as a brother, an uncle, a grandfather abuses his younger relative, etc. Such actions are usually sexual molestations or sex-related offenses. For example, the husband uses physical force to have sex with his wife in a way that she does not like or want or has sex with her without caring about her pleasure. The husband forces his wife to sell or have sex with other men. The husband rapes his wife, etc. (Kanjanakul, 1997; Intarajit \& Karinchai, 1999; Suwannarat, 2002; Archawanitkul \& Im-am, 2003; Promrak, 2007).

\subsection{Causes of Domestic Violence between Spouses in Thailand}

There are many factors related to causes of domestic violence between spouses in Thailand. It can be concluded from various studies that there are 13 causes of domestic violence between spouses in Thailand (Hemmanad, 
1990; Kanjanakul, 1997; Klongpayabarn, 1999; Kaewfan, 2007; Parimutto, 2010; Daen-khunthod, 2011)

1) The length of time spent together-Each day family members spend time interacting with each other for many hours, so there are more opportunities for domestic violence to happen among them when compared with other groups of people with whom they also spend time much time such as colleagues and friends. This indicates that in addition to the length of time spent together, there are other factors related to it.

2) The scope of activities and interest-Interactions between other groups of people usually has specific purposes. However, interactions between family members cover a wider range of activities. Therefore, there are more chances for conflict and unexpected incidents to take place.

3) Relationship strength-Family members have close relationships with each other, so when one of the family members does something wrong, other members feel more worried than when an outsider does the same thing. Moreover, it has to do with the strength of the relationship. Conflict between people who have close relationships between them is usually more intense than between strangers because people who have close relationships with each other will try to hide their feeling which when accumulates to a point, it can explode. The day it explodes, it may not be only about the cause of that particular conflict but also other related factors. The closer the relationship, the stronger the emotion and the stronger the explosion which tends to increase the anger and dissatisfaction. When the feelings are kept or suppressed for a long time, they can cause domestic violence.

4) Conflict of interest-Activities in a family can be a waste, and members of the family may want the opposite. That is, when one gains from doing one activity, the other might lose from doing it. Conflict can originate from different interest such as one member may want to go to a movie while another want to play sports. Conflict can also result from different characteristics such as one is messy but the other is tidy and has to clean up after him or her.

5) Age and gender differences-Family members are different in their ages and genders, so they have different perspectives and cultures, and thus, there exists conflict between the husband and wife, and parents and children. In addition, value, socio-economic conditions, technological advances, cultural patterns, generation gap that makes adults and teenagers see things differently can cause differences in their relationships.

6) Childhood experiences of violence-Individuals' learning and absorption of violence from society and environments especially in childhood in a family that regularly uses violence, children can absorb violence and use it. They would see that violence is normal and believe that problems can be solved with violence.

7) The role from birth-Gender equality designated by society is different basically and biologically. In society where gender discrimination in the family is emphasized, conflict is likely to happen. Even in families where there is no gender discrimination, latent conflict still exists. In families where husbands play a dominant role and want their wives to agree in all matters and to be dependent on them, they make their wives think that divorces can severely affect their children.

8) Family's privacy-In many societies, there are rules that prevent others to control or solve problems of domestic violence.

9) A high level of stress-Relationships of people in nuclear families is insecure because of many factors. Generally, relationships in nuclear families tend to be insecure because they have to face with important structural changes in the life cycle such as birth, children's coming of age, children's stages of development, aging, retirement, etc. These changes can emotionally affect family members and this group of families has a higher level of stress than other groups of families.

10) Involuntary membership-The relationship between husband and wife is an involuntary relationship. This means that society expects spouses to live together until death takes them apart including other factors that make it necessary for them to live together such as responding to emotional need of the other, properties, law, etc. When there is conflict or unhappiness, it is difficult to solve this kind of problem. Consequently, they have to continue living together, and the conflict or unhappiness increases as time passes, especially for nuclear families.

11) Knowledge about life history of each other-Family members know life history of each other well such as ability, weak points, strong points, likes and dislikes, etc., which is different from members of other systems who know each other superficially. Therefore, conflict between family members can be more severe than that between members of other systems because they can attack the other exactly on his or her weak points or defects.

12) Social values and attitudes of surrounding people-Wrong beliefs about status with emphasis on male dominance that men must be heads of families and males' aggressiveness and violence are normal and macho. 
On the contrary, women must not be aggressive and violent because that is not what ladies should be. Good wives must be modest, humble, and patient, not haggle with their husbands, respect their husbands, obedient, and ready to serve their husband in all matters. Another belief is that husbands are owners of their wives and have rights to do anything with them even beating them for punishment, and their wives do not have the right to protest them. Moreover, other people should not interfere when husbands and wives quarrel because it is normal just like the tongue and teeth hitting each other. When fathers beat their children, they have the power to do it and other people should not pay attention to it. There is another belief that it is normal for married men to have sexual with other women but not for married women to do so because it is considered adultery, and such women are bad and nobody would want to be associated with.

13) In society without alertness to human rights that does not believe all human beings are equal in rights, it is normal for people in such society to see some people as having higher status and more rights than other people do. Women and children have a lower status than men have and thus have less rights, and this causes abuses against them and causes them to be taken advantage of. In society where violence is so widely used that it becomes normal and accepted, where the use of violent behaviors reflects advantage and becomes incentive for using more violence, and where environments have influence on violence, pressure, thought, people in such society will be aggressive and likely to commit more acts of violence.

In addition, Supanichwatana and Laeheem (2017) specifies that domestic violence between spouses in Thailand can first happen at any stage of time they live together. The starting point is when they face problems between them and then so much stress is built up that negative interaction occurs. When husbands lose control of their emotion, even trivial arguments can result in violence and the first physical assault occurs. After that, the vicious circle of violence begins. That is, stress leads to argument or quarrel and physical assault. The circle usually finishes by the husbands' repentance and the wives' forgiveness. However, the couple does not actually deal with the problem and again fall into this vicious circle which usually becomes more intense. The three main reasons for violence against spouses are as follows.

1) Conflicts in living everyday life such as different habit, attitude, and personality as of an individual or that inherited from each own family. Husbands can be a beau, quick-tempered, aggressive, and addicted to something such as alcohol.

2) Problems related to the family life such as finance, life quality and problems of family members who are not aware of their roles and responsibility.

3) Severe family conflicts such as adultery, serious quarrel which leads to physical assault on each other or domestic problem which is not possible to handle and so finally the family can be broken.

\subsection{Effects of Domestic Violence between Spouses in Thailand}

The use of domestic violence between spouses in Thailand usually leads to unbalanced families and many more complicated problems such as broken home, abandoned children, elderly people's lack of care, etc. Domestic violence affects married couples. Physical and mental injuries because of divorces and other results from domestic violence are all dangers for all parts of society. Every incident of domestic violence causes losses physically, mentally, and socio-economically for the victims who are family members. According to Kanjanakul (1997), domestic violence between spouses incurs enormous economic burden to society in expenses of medical treatment, social welfare, counseling for victims, and implementations of preventive measures. Hemmanad (1990) specifies that injuring one's life physically can have long-term social effects on children's learning because children can absorb violence through training and socialization. Puawongpaet (1994) and Triemchaisri (2001) further specify that parents' quarrelling and injuring each other can affect children mentally, emotionally, and affect their learning as well because the beating and scolding usually link to children, too. Studies about vagrant children, drug-addicted children, and children who steal and injure others found that these children are generally from families that use violence. A study by Promrak (2007) found that domestic violence between spouses affected three groups of people concerned. The first group is individuals who are physically injured whose external wounds have to be treated and whose internal wounds can be hidden inside all their life. Most mental injuries are not treated or cured but can be treated by realization of their personal values. The second group is other family members, especially young children or teenagers who are directly and severely affected mentally. These children have negative image of family relationships that affect their life value making them aggressive, roguish, and not concentrative in their studies. The third group is people in society or the community. In low-income families, whether or not the parents are divorced or not divorced, children may run away from home and become vagrant children that are either a short-term or a long-term social problem.

In addition, domestic violence between spouses can affect the victims physically and mentally and it can also 
affect people around them. For example, in a case that the father hits the mother, children may be hit, too. Children, who are hit, injured or see violence regularly can have long term bad memories about the incidents. They may misunderstand that when they have a problem they can solve it with violence. Actually all problems should be solved with reasoning, talking it over, and understanding each other. In the case where children are in violent environments among their peers, when they grow up they may commit violent acts to their own families and pets. It can be seen that violence can be passed down from parents to children and grandchildren. If we let violence happen no matter how much it is, it will remain in society. That is why we must prevent violence to continue as a vicious cycle. Domestic violence between spouses affects three groups of people. The first group is the victims who are injured from slightly too as severely as death. Minor injuries range from bruises, swollen, and sore, etc. while severe injuries range from broken bones like the nose bridge, jaw, arm, etc. to bruised or ruptured internal organs, etc. Hospitalization due to server injury and being mentally affected can make the victim psychologically traumatized, frightened, suspicious, desperate, losing power and self-esteem. It starts from the stage of being shocked and not believing that such an incident could happen to them, and thus they usually deny it. Later when they can accept it, they are in the stage of feeling lonely and weak, which can make them unconscious. The next stage is reviewing life in the past and determining to make everything better, and the stage of feeling mentally wounded. Victims of severe domestic violence can be engaged in psychological regression or engaged in behavior that is associated with younger age such as being weak, giving in, and self-indulgent, etc. If this stage is persistent, the victims may imitate the aggressiveness called "transferred illness", which refers to women who are abused by their husbands all the time and they eventually imitate the aggression towards them and take it to themselves and possibly to their children, too. The second group of people affected by domestic violence is the family. Any family with regular domestic violence cannot be a good family because relationships between family members are damaged, and the key persons in the family, which are the husband and wife or parents, cannot perform their duties well. As a result, the family is unhappy, feeling distant, lacking love, unity, and trust. This kind of family cannot exist normally in society. Eventually, a divorce takes place causing a broken home and children may imitate the violent behavior they have witnessed. The third group of people affected by domestic violence is society. Domestic violence between spouses affects happiness and socio-economics and can be a never-ending problem transferred to the younger generations. Therefore, it is necessary for society to understand the problem clearly, realize the violence and help prevent it to happen in the future. Quarrelling, scolding, and battering in the family disturb neighbors and peace in the community. The cost for solving the problem cannot be estimated because it includes product losses caused by abusers and victims. One cause of the problem of vagrant children is broken homes. These children not only reflect a bad image for society and the country but also cause social problems for themselves and society because they do not go to school to be part of country's development. This causes the state to lose human resources and a lot of money to solve the problem (Siriwattana, 1995; Klongpayabarn, 1999; Triemchaisri, 2001; Siprasert, 2005; Kungsakon \& Pojam, 2008).

\section{Conclusions and Recommendations}

Domestic violence between spouses in Thailand is a pattern of actions characterized by the use of force to hurt others physically, mentally, hygienically, and sexually, and to damage others properties, to force, threaten, injure physically, confining, delaying, sexually assaulting and molesting, neglecting, and not looking after when ill. Domestic violence between spouses includes invasion of personal rights and freedoms which can be violence committed by adults against children, their spouses or the elderly, etc. and which can be violence committed by children or youths against their siblings or parents, etc. In addition, domestic violence between spouses refers to acts or behaviors intended to hurt each other among family members and physically, mentally, and emotionally injure others. Physical injuring includes battering, slapping, kicking, punching, etc. which sometimes can lead to injuries or death while mental injuring includes speaking aggressively, scornfully, sarcastically, impolitely or in a threatening way. Moreover, domestic violence refers to rape, confining, delaying, obstructing meeting with relatives and friends, and mentally oppressing or bullying, etc., which cause the victim to be frightened, suspicious, emotionally shaken, depressed, and unconfident.

Domestic violence between spouses in Thailand can be classified according to people involved into three categories: violence committed against oneself, violence between individuals committed by other individual or groups of individuals, and violence between large groups of people, and social violence. In addition, violence can be classified according to actions into three categories: physical violence in which the victim is physically injured; mental violence in which the victim is mentally hurt or loses rights and freedoms; and sexual violence in which the victim is sexually harassed and violated. There are many causes of domestic violence between spouses in Thailand but one of the important causes might be patriarchy with a belief that men hold authority over the 
family. Moreover, some social environments can contribute to domestic violence such as the high rate of crimes, pornographic media and other violent media, etc. Violent childhood experiences in which children learn and absorb violence from society and environments can cause domestic violence. Some other causes include time spent together in doing activities that causes clashes, stress and conflict; and lack of time spent together to understand, talk openly or reveal feelings because all family members focus on their own work outside and inside the home, which result in estranged relationships. Physical and mental immaturity or being not ready for married life, problems related to technological and communication globalization, and socio-economic crisis can minimize family relationships resulting in misunderstanding, lack of love and care, not being able to accept the other's behavior, and being unable to adapt to each other, can all be causes of domestic violence. When the family faces problems and lacks suitable problem-solving skills, conflict can take place and if conflict has accumulated for a long time, it can eventually become domestic violence.

Domestic violence between spouses in Thailand affects many people from the family level in which family members are injured, learn and absorb violence, unhappy, and can lead to divorces. Furthermore, it affects the community in that it can cause disorders, and disturbance to the neighborhood and it can cause children to run away from home and become homeless. At the community level, violence can spread to neighbors, children imitating violent behavior and use violence in school and the community. At a national level, domestic violence between spouses can incur expenses for medical treatment of the victims, salaries for related personnel, and expenses for campaigns to terminate and prevent problems caused by mass media.

The results of the study can be used as a guideline for preventing and reducing domestic violence between spouses. Parents and guardians must realize and give importance to avoidance of the use of violence between family members. They must be patient, forgive, understand, and trust each other for the sake of happiness in the family. In addition, relatives and related agencies should cooperate in promoting happy family life, resisting the use of domestic violence, and assisting parents who regularly quarrel and physically hurt each other by organizing training for them in order to socialize and rehabilitate them. Furthermore, other methods can also be used to assist such families to reduce and stop violence, which would result in their having peacefully happy families in which there is love and unity. The results of the study can also be useful for students, teachers, lecturers, educators, and those interested in using it as a guideline for conducting further studies related to domestic violence between spouses.

\section{Acknowledgements}

I would like to thank the Research Fund, Faculty of Liberal Arts, Prince of Songkla University for its financial support.

\section{References}

Archawanitkul, K., \& Im-am, W. (2003). Violence against women. Bangkok: Institute for Population and Social, Mahidol University.

Arpapirom, A. (2000). Violent scenes in globalization. Bankok: Ammarin Printing and Publishing.

Daen-khunthod, C. (2011). Domestic violence: A study of wives being assaulted by husbands in Nakhon Ratchasima (Unpublished master's thesis). Rajabhat Nakhon Ratchasima University, Nakhon Ratchasima.

Friends of Women Foundation. (1989). Manuals of domestic violence problem. Bangkok: Friends of Women Foundation.

Friends of Women Foundation. (2013). Situations of domestic violence in the year 2012. Bangkok: Friends of Women Foundation.

Hemmanad, H. (1990). Family violence: The case of study low income husbands in municipal areas Muang District, Ubonratchathani Province (Unpublished master's thesis). Thammasart University, Bangkok.

Intarajit, I., \& Karinchai, N. (1999). Women and Children: The victim of domestic violence. Bangkok: Institute of Psychology Hot Line.

Kaewfan, K. (2007). Domestic violence: A case study of woman labor in factories in Saraphi District, Chiang Mai and violence against spouses (Unpublished master's thesis). Chiang Mai University, Chiang Mai.

Kanjanakul, C. (1997). A domestic violence: A study of wife battering (Unpublished doctoral's dissertation). Srinakharinwirot University, Bangkok.

Klongpayabarn, B. (1999). Family violence: The factor associated with wives violence in Muang district, Srakaeo province (Unpublished master's thesis). Mahidol University, Bangkok. 
Kongsakon, R., \& Pojam, N. (2008). Family violence. Bangkok: Srinakharinwirot University.

Ministry of Social Development and Human Security. (2007). Protection victim statute with domestic violence 2007. Bangkok: Ministry of Social Development and Human Security.

One Stop Crisis Center (OSCC). (2011). Statistics of women and children seeking asylum at OSCC. Bangkok: OSCC.

Oopyokin, P. (1995). The analysis of the problem of domestic violence. STOU Journal, 8(3), 99-107.

Pakjekwinyusakul, W., Jamsutee, U., \& Nettayasupa, A. (2003). Evaluation of the judicial proceedings response to family violence. Bangkok: Pim-aksorn.

Parimutto, A. (2010). Family conflict solution applied from Theravada Buddhism Dhamma (Unpublished master's thesis). Mahachulalongkornrajavidyalaya University, Bangkok.

Pichaisanith, P. (1997). Family development. Bankok: Ammarin Printing and Publishing.

Pongwech, M., \& Wijitranon, S. (2000). Dissection stalemate: Gender and domestic violence. Bankok: Gender and Development Research Institute.

Pradabmuk, P. (2003). Family violence: State of the art review and research promoting system in the future. Nontaburi: Health Systems Research Institute.

Promrak, T. (2007). Women and domestic violence: Divorce as the solution (Unpublished master's thesis). Thammasart University, Bangkok.

Puawongpaet, S. (1994). Thai family: The problems and solutions. Journal of Public Welfare, 37(6), 20-24.

Punamsap, W. (2005). Problems and solutions of domestic violence (Unpublished master's thesis). Krirk University, Bangkok.

Siprasert, Ph. (2005). Domestic violence: Wives assaulted cases (Unpublished master's thesis). Kasetsart University, Bangkok.

Siriwattana, S. (1995). Domestic violent problem: A case study of psychological impact (Unpublished master's thesis). Thammasart University, Bangkok.

Songsumpan, C. (2002). Violence in Thai society. Political Substances, 23(2), 144-148.

Supanichwatana, S., \& Laeheem, K. (2011). Violence against Spouses in Thailand. In $6^{\text {th }}$ International Conference on Humanities and Social Sciences. Faculty of Defence Studies and Management, National Defence University of Malaysia in conjunction with Faculty of Liberal Arts, Prince of Songkla University, pp. 13-18.

Suwannarat, K. (2002). The self-empowerment of women experiencing domestic violence (Unpublished master's thesis). Thammasart University, Bangkok.

Triemchaisri, S. (2001) Violence against women: The effects of violence and its prevention. The Journal of Nursing Science, 50(1), 8-15.

Violence against Children and Women and Domestic Violence Information Center. (2013). Annual report on domestic violence cases. Bangkok: Ministry of Social Development and Human Security.

Wichitranon, T. S., \& Phongwet, M. (2000). Development of information systems and indicators of violence in Thailand. Bangkok: Gender and Development Research Institute.

Yoddamnoen-Adtidge, B. (2003). Violence against spouses and women's health. Bangkok: Population and Social Research Institute, Mahidol University.

\section{Copyrights}

Copyright for this article is retained by the author(s), with first publication rights granted to the journal.

This is an open-access article distributed under the terms and conditions of the Creative Commons Attribution license (http://creativecommons.org/licenses/by/3.0/). 